\title{
Methoxychlor as a Model for Environmental Estrogens
}

\section{Audrey M. Cummings}

To cite this article: Audrey M. Cummings (1997) Methoxychlor as a Model for Environmental Estrogens, Critical Reviews in Toxicology, 27:4, 367-379

To link to this article: http://dx.doi.org/10.3109/10408449709089899

\section{曲 Published online: 25 Sep 2008.}

Submit your article to this journal $\pi$

\section{Article views: 76}

Q View related articles $\sqsubset$

4 Citing articles: 8 View citing articles 준 


\title{
Methoxychlor as a Model for Environmental Estrogens
}

\author{
Audrey M. Cummings* \\ Endocrinology Branch, Reproductive Toxicology Division, NHEERL, USEPA, Research Triangle Park, NC \\ * Address all correspondence to: Audrey M. Cummings MD-72, NHEERL, USEPA, Research Triangle Park, NC 27711
}

\begin{abstract}
Estrogens can have a variety of physiological effects, especially on the reproductive system. Chemicals with estrogenic activity that are present in the environment may thus be considered potentially hazardous to development and/or reproduction. Methoxychlor is one such chemical, a chlorinated hydrocarbon pesticide with proestrogenic activity. Metabolism of the chemical either in vivo or using liver microsomes produces 2,2-bis(p-hydroxyphenyl)- 1,1,1-trichloroethane (HPTE), the active estrogenic form, and the delineation of this mechanism is reviewed herein. When administered in vivo, methoxychlor has adverse effects on fertility, early pregnancy, and in utero development in females as well as adverse effects on adult males such as altered social behavior following prenatal exposure to methoxychlor. Effects of methoxychlor on the female have been studied extensively, whereas reports on the chemical's effects on males are less common. From the studies reviewed here, the reproductive toxicity of methoxychlor is evident, but the significance of this toxicity with respect to human health remains to be determined.
\end{abstract}

KEY WORDS: methoxychlor, proestrogen, HPTE, estrogenic pesticide.

\section{INTRODUCTION}

Any exogenously administered estrogen can have toxic effects, depending on the dose applied. For example, estrogen administered during early pregnancy can block implantation or terminate pregnancy. ${ }^{1,2}$ This hormone can also accelerate embryo transport through the reproductive tract that, in itself, can impair early pregnancy. ${ }^{3}$ Effects of excess estrogen on the decidualization of the uterus, a growth and differentiation of the endometrium that is necessary in the rat and human for implantation, can include a reduction or obliteration of decidual tissue formation. ${ }^{4,5}$ However, the same hormone that has all of these effects is necessary for pregnancy and decidualization when present at the proper levels and in proportion with progesterone.

The mechanism by which estrogen exerts many of its effects is well known (Figure 1). The circulating hormone binds to a receptor molecule in the cytoplasm or nucleus of target cells (those cells of organs containing receptors). When the steroid hor- mone binds to its receptor, a conformational change results in active or transformed receptors. The active, dimer form binds to the genome at an acceptor site or steroid response element (SRE), thus activating or inhibiting the transcription of specific messenger RNAs. Estrogen-induced mRNAs are subsequently processed and then translated by ribosomes in the cytoplasm to produce a new protein, such as an enzyme. This new protein thus alters the function of the cell and, ultimately, the hormone target tissue. ${ }^{6}$.

The uterus is a primary target organ for estrogens. Estrogen is uterotrophic. The administration of estrogen to immature or ovariectomized rats will result in the rapid growth of uterine tissue, imbibition of fluid, and increase in uterine weight by $6 \mathrm{~h}^{7}$ Estradiol can promote the activity of a number of uterine enzymes, including ornithine decarboxylase, ${ }^{8}$ creatine kinase, ${ }^{9,10}$ uterine peroxidase, ${ }^{11,12}$ glucose-6-phosphate dehydrogenase, ${ }^{13}$ and others. The uterotrophic response and these specific enzyme activities have been used as markers for the action of environmental estrogens in animals. 


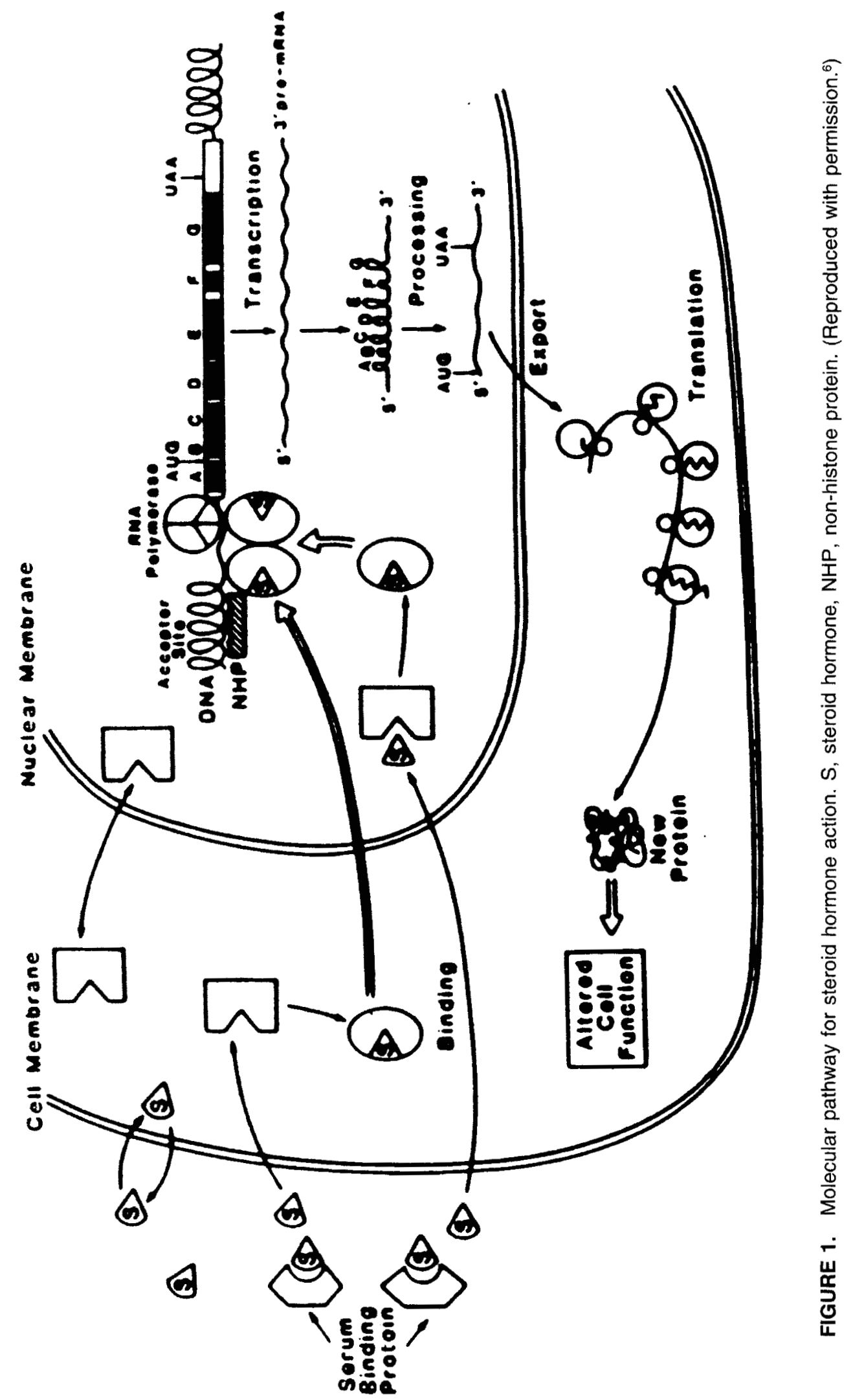


Estrogens have significant effects following perinatal exposure, specifically in brain and reproductive tract development. Perinatal administration of estrogen can induce a male pattern of brain differentiation. ${ }^{14}$ The synthetic estrogen diethylstilbestrol (DES), administered to rodents perinatally, can reduce fertility and produce structural abnormalities of the oviduct, uterus, cervix, and vagina. ${ }^{15,16}$ DES also alters sex differentiation of the rodent central nervous system, where, for example, the sexually dimorphic nucleus in the preoptic area (SDN-POA) of the rat hypothalamus is considerably larger in male rats than in females. ${ }^{14}$

DDT was one of the first estrogenic pesticides found in the environment to be banned. Originally, Burlington and Lindeman ${ }^{17}$ demonstrated that DDT inhibited testes growth and secondary sexual characteristics in cockerels, suggesting that it was estrogenic. Later it was reported that $2,2^{\prime}$-bis-( $p$-hydroxyphenyl)-1,1,1-trichloroethane appeared to have estrogenic activity, while DDT did not. ${ }^{18}$ When $o, p^{\prime}$ DDT (1,1,1-trichloro-2( $p$ chlorophenyl)-2-( $o$ - chlorophenyl)ethane) was compared with $p, p^{\prime}$-DDT by the measure of increased uterine and oviductal weight, water content, glycogen and RNA in rats, chickens, and quail, $o, p^{\prime}$ but not $p, p^{\prime}$-DDT was found to be estrogenically active. ${ }^{19}$

Further work with DDT analogues have shown that $500 \mu \mathrm{g}$ of $o, p^{\prime}$-DDT injected daily into young rats advances vaginal opening and increases ovarian and uterine weights. ${ }^{20}$ In mature ovariectomized rats, $o, p^{\prime}$-DDT treatment with $10 \mathrm{mg} / \mathrm{d}$ resulted in an increase in uterine weight, a thickened vacuolated uterine epithelium, and the induction of cornified vaginal smears with reduced serum luteinizing hormone (LH). ${ }^{20}$ Two homologues of DDT, $p, p^{\prime}$-DDD (2,2-bis(p-chlorophenyl)-1,1-dichloroethane) and $p, p^{\prime}$-DDE (2,2-bis ( $p$-chlorophenyl)-1,1-dichloroethylene) were not estrogenic in these studies, while one of the major metabolites of $o, p^{\prime}$-DDT, $p, p^{\prime}$-DDA (2,2-bis(p-chlorophenyl) acetic acid) was found to exhibit estrogenic activity.

Chlordecone (Kepone) is another pesticide with estrogenic characteristics that is no longer used due to its toxicity. ${ }^{21}$ Kepone has been shown to produce uterine growth in weanling rats at doses of 10 to $100 \mathrm{mg} / \mathrm{kg}$; the chemical also produced precocious vaginal opening, persistent vaginal estrus, and anovulation. ${ }^{22}$ The polychlorinated biphenyl (PCB) Aroclor 1221 produced uterine growth in weanling rats, and when administered to pups on days 2 and 3 of life it induced precocious puberty and persistent vaginal estrus, which are hallmarks of an estrogen. ${ }^{23}$ Using the 18-h glycogen response of the immature rat uterus, Bitman and $\mathrm{Cecil}^{24}$ evaluated a number of PCB compounds. PCB's numbers 43, 44, 45, and 46 (corresponding to Aroclors 1221, 1232, 1242, and 1248) were shown to be estrogenically active. 4Octylphenol is a wastewater treatment plant effluent chemical that is a breakdown product of detergents. It blocks early pregnancy in rats (unpublished data) and has been shown to be estrogenic. ${ }^{25}$

Methoxychlor (MXC) is a pesticide that was developed to replace DDT. Considerable interest has been paid to MXC due to the fact that it continues to be used, is found in the environment, and is a proestrogen.

\section{GENERAL CHARACTERISTICS OF METHOXYCHLOR}

Methoxychlor has a chlorinated, double ring structure (Figure 2). Technical-grade MXC contains 50 to $88 \%$ of the pure chemical, and the remainder is isomers and reaction products. It was first synthesized in 1893, and commercial production in the U.S. began in 1946. MXC is approved for use as an insecticide on 87 agricultural crops and on beef cattle, dairy cattle, goats, sheep, and swine. ${ }^{26}$ Tradenames include Maralate, Marlate, and Metox, and the chemical name is 2,2-di(p-methoxy phenyl) 1,1,1-trichloroethane.

A report published in $1983^{27}$ stated that MXC was found in $1.2 \%$ of composite samples of food in the U.S., representing an intake of 0.1 to $0.8 \mu \mathrm{g}$ $\mathrm{MXC/d}$ for 16- to 19-year old males. When administered orally to mice, $98.3 \%$ of the MXC is eliminated by $24 \mathrm{~h} .{ }^{28}$ Both mice and insects metabolize methoxychlor to 2-( $p$-hydroxyphenyl)-2-( $p$ methoxyphenyl)-1,1,1-trichloroethane and 2,2-bis( $p$-hydroxyphenyl)-1,1,1-trichloroethane via O-demethylation. ${ }^{28}$ When rats were fed methoxy- 


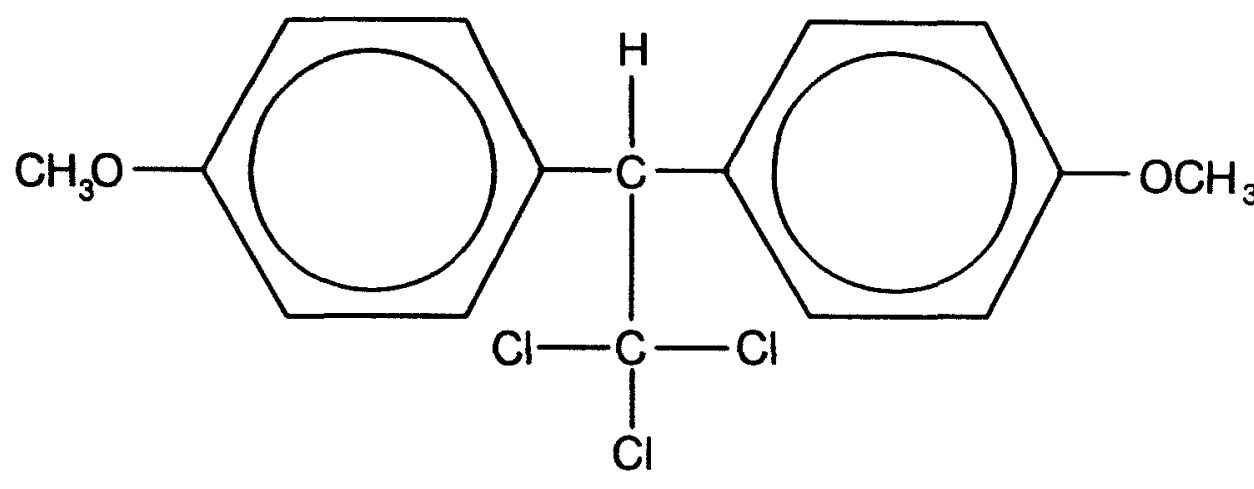

CHEMICAL FORMULA: $\quad \mathrm{G}_{16} \mathrm{H}_{15} \mathrm{Cl}_{3} \mathrm{O}_{2}$

FIGURE 2. Structure of methoxychlor: 1,1,1-trichloro-2,2-bis(p-methoxyphenyl)ethane. (By permission, Ref. 6.)

chlor at $25 \mathrm{mg} / \mathrm{kg}$ in the diet, the chemical was not detected in body fat at 18 weeks. ${ }^{29}$ Rats receiving MXC in the diet for 2 years at 25, 200, or 1600 $\mathrm{mg} / \mathrm{kg}$ did store the chemical in the fat, and $\mathrm{MXC}$ was also found in the kidney, liver, and brain. ${ }^{30}$

The first publication of a chronic oral study was published in $1950 .{ }^{31}$ The $\mathrm{LD}_{50}$ in rats at $72 \mathrm{~h}$ was found to be $5 \mathrm{~g} / \mathrm{kg}$ for the technical-grade MXC. The purified (recrystallized) material was less toxic; at $72 \mathrm{~h}$ a mortality of $10 \%$ was observed at $5.8 \mathrm{~g} / \mathrm{kg}$. No specific abnormalities were recorded after necropsy and histopathological evaluation except for a drastic reduction in testes weight and atrophic changes indicated in sections of the treated testes. This level of toxicity is considerably less than that of DDT $\left(\mathrm{LD}_{50}=0.25 \mathrm{~g} / \mathrm{kg}\right.$ ), the pesticide that MXC was expected to replace. More recently, the toxicity of MXC was examined in the freshwater teleost Puntius conchonius. ${ }^{32}$ It was found that there was selective damage to the oocytes in the absence of general toxicity.

The majority of investigators reporting on the carcinogenicity of $\mathrm{MXC}$ concluded that the results were negative, ${ }^{33,34}$ although a few reports found positive results. ${ }^{35} \mathrm{~A}$ similar apparent contradiction was raised in a recent report where MXC was shown to be positive for mutagenicity in the mouse lymphoma assay (MLA) but negative in the Chinese hamster ovary cell (CHO) assay. ${ }^{36}$ After taking into account all of the data, positive and negative, the National Cancer Institute concluded that methoxychlor is not an animal carcinogen. ${ }^{37}$

\section{CHEMISTRY OF METHOXYCHLOR AND ITS MECHANISMS}

In one of the early studies investigating the chemical mechanism of the effects of methoxychlor, a report by Welch, Levin, and Conney ${ }^{38}$ showed a parallel increase in rat uterine weight $6 \mathrm{~h}$ after methoxychlor administration, and a decrease in the uptake of $17 \beta$-estradiol by the rat uterus if $50 \mathrm{mg} / \mathrm{kg} \mathrm{MXC}$ was administered $2 \mathrm{~h}$ prior to labeled estradiol in vivo. In a study where various chlorinated hydrocarbons, including $\mathrm{MXC}$, were added to a rat uterine supernatant preparation, both technical and purified MXC inhibited the binding of ${ }^{3} \mathrm{H}$-estradiol in vitro; a parallel increase in uterine weight was found following in vivo administration. ${ }^{39}$ Evidence that the induction of hepatic monooxygenase by pretreatment of animals with $\mathrm{CCl}_{4}$ interferes with the uterotrophic action of the chemicals tested ${ }^{38}$ suggested that metabolite(s) of MXC were the active species binding to the estrogen receptor. ${ }^{40}$ Methoxychlor and technical methoxychlor were shown to be more effective inhibitors of ${ }^{3} \mathrm{H}$ - estradiol binding if they had been pretreated with liver microsomes, suggesting that 
some metabolite of MXC has a higher affinity for the receptor than does $\mathrm{MXC}^{41}$

Investigations by Bulger, Muccitelli, and Kupfer $^{42}$ revealed that laboratory-grade MXC was contaminated with a material that specifically bound the estrogen receptor from rat uterus. The contaminant was eliminated by base washing, suggesting the presence of an acidic, phenolic compound. The base-washed, recrystallized MXC did not translocate the estrogen receptor, whereas the phenolic contaminant was shown to compete with ${ }^{3} \mathrm{H}$-estradiol for binding to the receptor. When the DDT analog 2,2-bis(p-hydroxyphenyl)-1,1,1-trichloroethane (HPTE), known to be a major metabolite of methoxychlor, was investigated, HPTE was shown to markedly inhibit the binding of ${ }^{3} \mathrm{H}-\mathrm{E}_{2}$ with high affinity. It was concluded, albeit erroneously, that the estrogenic activity of MXC results from the activity of a contaminant and that the contaminant may be HPTE. In a subsequent report ${ }^{43}$ evaluations using ornithine decarboxylase (ODC) activity (an indication of estrogenic activity) and uterotrophic activity showed that both laboratory-grade and purified methoxychlor ( $5 \mathrm{mg} / \mathrm{rat}$ ) stimulated both parameters after $7 \mathrm{~h}$, indicating that methoxychlor was active in vivo. However, $100 \mu \mathrm{g} / \mathrm{rat}$ of HPTE markedly elevated ODC activity and uterotrophic activity after $6 \mathrm{~h}$. The higher potency of the MXC metabolite, HPTE, and the shorter time required for its activity suggested that, in vivo, methoxychlor is bioactivated to an estrogen metabolite that may be HPTE. Subsequently, methoxychlor was incubated with hepatic microsomes, and the resulting metabolites were isolated and recovered via thin layer chromatography (TLC). Results indicated that methoxychlor is O-demethylated in vitro by rat liver microsomes and that methoxychlor demethylase activity is enhanced by pretreatment of animals with an inducer of hepatic monooxygenase activity. When extracts from the hepatic incubations were evaluated for receptor binding, it was found that the demethylation products of methoxychlor inhibit ${ }^{3} \mathrm{H}-\mathrm{E}_{2}$ binding to the $8 \mathrm{~S}$ estrogen receptor of rat uterine cytosol under both saturating and non- saturating conditions with respect to ${ }^{3} \mathrm{H}-\mathrm{E}_{2}$. Identification of the metabolites separated by TLC revealed the presence of a compound chromatographically identical to HPTE. Three metabolites were tested, and while all produced an inhibition of ${ }^{3} \mathrm{H}-\mathrm{E}_{2}$ binding to receptor preparations, HPTE and the parallel metabolite were most effective in inhibiting the binding of ${ }^{3} \mathrm{H}-\mathrm{E}_{2}$ to uterine cytosol. In a landmark paper by Kupfer and Bulger, ${ }^{44}$ the authors defined a proestrogen as a compound that requires metabolic activation to achieve the translocation of the cytosolic estrogen receptor $\left(R_{c}\right)$ into the nucleus, yielding an increase in the nuclear form $\left(R_{n}\right)$. Initially, it was shown that the incubation of purified methoxychlor with rat uteri did not cause the translocation of the estrogen receptor. Both 17 $\beta$-estradiol and HPTE decreased cytosolic estrogen receptors $\left(R_{c}\right)$ and elevated nuclear estrogen receptors $\left(R_{n}\right)$. Methoxychlor and $o, p^{\prime} D D T$ were independently incubated with rat liver microsomes in the presence of immature rat uteri. The effect of metabolism on the distribution of cytosolic $\left(\mathbf{R}_{c}\right)$ and nuclear $\left(\mathbf{R}_{n}\right)$ estrogen receptors was determined. The incubation of methoxychlor resulted in diminished $R_{c}$ and elevated $R_{n}$. These data, with the range of appropriate controls, showed that the transformation of MXC by rat liver microsomes into chemicals with high estrogen-like activity is catalyzed by the microsomal monooxygenase system. The chemical o,p'DDT had equivalent estrogenic activity with or without metabolic activation, signifying that it is estrogenic, not a proestrogen.

Based on the prior knowledge ${ }^{28}$ that the major metabolites of MXC result from O-demethylation and consist of a mono- and a bis-phenol, Ousterhout et al. ${ }^{45}$ synthesized the two compounds and evaluated the ability of each chemical to inhibit the binding of $\mathrm{E}_{2}$ to rat uterine cytosol in vitro. The bis-phenol had a higher affinity for the receptor as indicated by the fact that a lower concentration was necessary to inhibit $\mathrm{E}_{2}$ binding by $50 \%$. Sucrose density gradient centrifugation showed that $E_{2}$ was displaced from the $8 \mathrm{~S}$ receptor by the bis-phenol. Liver microsomal incubation of methoxychlor resulted in predominantly the mono-phenol. From these data, the authors erroneously concluded that the estrogenic effects of methoxychlor in vivo are primarily due to metabolism to the mono-phenol.

A report by Bulger, Feil, and Kupfer ${ }^{46}$ revealed the error of the conclusions of Ousterhout et $\mathrm{al} .{ }^{45}$ by using the liver microsome/rat uteri incubation technique to examine the identity and activity of the contaminants and metabolites of MXC. MXC was purified by base washing, recrys- 
tallization, and preparative HPLC. The in vitro determination of proestrogenic and estrogenic activity involved mixtures of rat hepatic microsomes (capable in the presence of NADPH of transforming the proestrogen into an active estrogen) and immature rat uteri (target monitor for $\mathrm{E}_{2}$ activity, where $E R_{i}$ and $E R_{n}$ are measurably changed) with or without NADPH for the proestrogenic vs. estrogenic activity, respectively. Compounds testing positive for estrogenic activity were subjected to a second in vitro assay, similar to the first, except that no microsomes were present in either vial. Compounds were also tested directly in vitro for (1) their relative binding affinity with ${ }^{3} \mathrm{H}$-estradiol in rat uterine cytosol and (2) saturation analysis of the inhibition of ${ }^{3} \mathrm{H}-\mathrm{E}_{2}$ binding to rat uterine cytosol. In metabolism studies, demethylation was determined for compounds by analyzing formaldehyde evolution. Finally, estrogenic activity in vivo was determined by the administration of compounds to immature female rats and, $6 \mathrm{~h}$ later, the evaluation of uterine weight and ODC activity. Of the 16 compounds (including methoxychlor) that make up $99.5 \%$ of technical-grade methoxychlor, MDDE (compound 34; 1,1-dichloro-2,2-bis(4-methoxyphenyl)ethane) and methoxychlor required metabolic transformation for estrogenic activity to be manifested. Two base soluble compounds, the monophenolic derivatives of methoxychlor and of MDDE (mono-OH-methoxychlor and mono-OH-MDDE) were active per se. When the two sets of demethylated metabolites of MDDE and of MXC were evaluated directly in the cytosolic estrogen receptor binding assay, the relative binding affinity (RBA) was found to be bis-OH-MDDE $>$ bisOH-MXC (HPTE) > mono-OH-MDDE > mono$\mathrm{OH}-\mathrm{MXC}$. Thus, the most active metabolite of MXC was shown to be HPTE, and components of technical-grade methoxychlor were shown to be either estrogenic per se, proestrogenic, or inactive.

\section{REPRODUCTIVE EFFECTS OF METHOXYCHLOR}

\section{A. Fertility and Related Mechanisms}

Treatment of rats with technical-grade MXC in the feed prior to breeding was extremely del- eterious to reproduction. Six weeks of treatment at 2500 or $5000 \mathrm{ppm}$ in the feed resulted in fewer matings, litters, and implantation sites.$^{47}$ Doses of $1000 \mathrm{ppm}$ did not impair fertility, but offspring were affected: deleterious effects included reduced mating and fewer litters. The time from birth to vaginal opening was shortened in pups from dams fed 1000 or $2500 \mathrm{ppm}$ MXC prior to breeding. Pups from control dams that were exposed to MXC from birth and postweaning exhibited reduced mating and fewer litters. MXC also produced persistent estrus, identified by vaginal smears, if administered long enough (5 weeks) and at high enough doses $\left(5000 \mathrm{ppm}\right.$ ) to adult females. ${ }^{47}$ (The authors point out the relative potency of technical MXC: $0.10 \mu \mathrm{g}$ diethylstilbestrol is equivalent to $1 \mathrm{mg}$ technical MXC, as derived from their previous work. ${ }^{24}$ ) In a similar study, groups of female rats received MXC at 100 or $200 \mathrm{mg} / \mathrm{kg} /$ day for $14 \mathrm{~d}$ prior to mating and throughout pregnancy. On gestation day 13, no implantations were found; evaluation of the ovaries revealed a lack of corpora lutea and follicular atresia. ${ }^{48}$ In another study, rats were dosed with $90 \%$ pure MXC from weaning through puberty and gestation to day 15 of lactation; doses ranged from 25 to $200 \mathrm{mg} / \mathrm{kg} / \mathrm{d}$ MXC..$^{49}$ The administration of 100 or $200 \mathrm{mg} / \mathrm{kg} / \mathrm{d}$ MXC produced a significant reduction in fertility; fertility was $0 \%$ at $200 \mathrm{mg} / \mathrm{kg} / \mathrm{d}^{49}$

In Tullner's original report in 1961, technicalgrade methoxychlor was first shown to produce an increase in uterine weight in rodents. ${ }^{50} \mathrm{~A}$ direct effect on the uterus was identified, and the author recognized that the active moiety was an isomer or contaminant of the technical-grade chemical. In work reported by Welch et al., ${ }^{38}$ purified MXC was used in the 6-h uterotrophic test and increased the weight of immature female rat uteri by $37 \%$ at 50 $\mathrm{mg} / \mathrm{kg}$. When purified MXC $(50 \mathrm{mg} / \mathrm{kg})$ was administered to immature rats $2 \mathrm{~h}$ prior to $1.5 \mu \mathrm{g} / \mathrm{kg}{ }^{3} \mathrm{H}-17$ $\beta$-estradiol, the chemical decreased the uptake of the tritiated estradiol by the uterus by $28 \%$ compared with a value of $61 \%$ for $30 \mu \mathrm{g} / \mathrm{kg}$ diethylstilbestrol. ${ }^{38}$ Relative binding to the estrogen receptor also appeared to be the critical factor in the initiation of implantation and maintenance of pregnancy by a variety of chemicals, including MXC in a hypophysectomized, progesterone-treated model of early pregnancy. ${ }^{51} \mathrm{MXC}$ was more successful than 
other polychlorinated hydrocarbons in initiating and maintaining pregnancy according to the degree to which the chemicals bind the estrogen receptor, thus supporting the role of the estrogen receptor in the biological effects of MXC. ${ }^{51}$

In an examination of estrogen-induced behavior and its modification by MXC, Gray et al.$^{52}$ used running wheel activity (RWA; an estrogenically controlled, normally cyclic phenomenon) and induced sex behavior. Exposure to MXC at $400 \mathrm{mg} / \mathrm{kg} / \mathrm{d}$ produced high levels of non-cyclic RWA and persistent vaginal estrus. When $200 \mathrm{mg} / \mathrm{kg} / \mathrm{d}$ MXC was administered to ovariectomized female rats and the animals then received progesterone, the progesterone blocked the MXC-stimulated increase in RWA, indicating a mechanism mediated by estrogen receptors in the CNS. ${ }^{52}$ Finally, MXC-treated, ovariectomized rats that were injected with progesterone displayed reproductive behavior, in a manner similar to estrogen plus progesterone-treated animals, where the estrogen and the MXC is acting on areas of the CNS other than those involved in RWA. ${ }^{52}$ However, unlike estrogen, MXC did not block the ovariecromy induced increase in FSH or LH. ${ }^{52}$

\section{B. Early Pregnancy}

When a range of dosages of MXC ( $98 \%$ pure) were administered to rats to evaluate the chemical's effect on early pregnancy, exposure was limited to days 1 to 8 of pregnancy (day $0=$ sperm + ). Doses of $300 \mathrm{mg} / \mathrm{kg} / \mathrm{d}$ and above reduced implantation sites to zero, $200 \mathrm{mg} / \mathrm{kg} / \mathrm{d}$ resulted in a significant reduction in the number of sites, whereas $100 \mathrm{mg} / \mathrm{kg} / \mathrm{d}$ had no effect when evaluations were made on day $9 .{ }^{53}$ Serum progesterone levels were reduced at all doses of MXC. A protocol in which the sensitivity of the preimplantation interval (days 1 to 3 ) is compared with the postimplantation interval (days 4 to 8) was applied to MXC. Whereas dosing with MXC during days 4 to $8 \mathrm{had}$ no effect, exposure during days 1 to 3 resulted in partial (at $200 \mathrm{mg} / \mathrm{kg} / \mathrm{d}$ ) or total (at $500 \mathrm{mg} / \mathrm{kg} / \mathrm{d}$ ) loss of embryos as judged by the number of implantation sites seen on day $9 .{ }^{53}$ Thus, the preimplantation interval was found to be more sensitive to the effects of MXC than the postimplantation period.

The decidual cell response (DCR) is a technique that utilizes the phenomenon of induced pseudopregnancy (a state endocrinologically corresponding to pregnancy but lacking fertilized eggs) and a surgical technique that induces a response from the uterus that mimics the growth and development of the endometrium that occurs during early pregnancy. ${ }^{54,55}$ The result is a uterus filled with decidual tissue, a deciduoma, that can weigh up to $2 \mathrm{~g}$ per horn. Estrogen and progesterone, in the proper amounts and ratio, are critical for the development of these deciduomata. Excess estrogen will impair both the development of the sensitivity of the uterus to stimulation and the growth of the tissue following induction. ${ }^{4,5}$ The administration of $98 \%$ pure MXC for $8 \mathrm{~d}$ to female rats prepared for the DCR inhibited the decidualization of the uterus in a dose-dependent manner: $100 \mathrm{mg} / \mathrm{kg} / \mathrm{d} \mathrm{MXC}$ had no effect, but doses of $200,300,400$, and $500 \mathrm{mg} / \mathrm{kg} / \mathrm{d}$ produced incremental inhibition of this phenomenon. ${ }^{56}$ These data suggest that MXC exerts an effect directly on the uterus (no effect on serum progesterone was found in this study), and such an effect may contribute to the antifertility effect of MXC. Using this system as a comparison between MXC and a positive control, estrone, the estrogenic activity of $98 \%$ pure MXC was estimated to be $1 / 20,000$ times the activity of estrone or $1 / 200,000$ times the activity of estradiol or DES. In a related study, ovariectomized rats hormonally prepared to reproduce pseudopregnancy and surgically induced on the proper day were treated with $500 \mathrm{mg} / \mathrm{kg} / \mathrm{d}$ MXC or oil. MXC blocked the DCR in the absence of ovaries, confirming a direct effect of the chemical on the uterus. ${ }^{53}$

Although direct effects on the uterus were evident, the sensitivity of the preimplantation interval of pregnancy to the effects of MXC indicated the presence of other potential mechanisms such as embryo transport rate, which is also susceptible to estrogenic effects. ${ }^{3} \mathrm{MXC}$ was administered on days 1 to 3 of pregnancy (day $0=$ sperm + ) and the distribution of the embryos between the oviduct and the uterus was assessed on the afternoon of day 1 and at morning and afternoon times on days 2 and 3. While no effect of MXC was seen on day 1 , on 
days 2 and 3 both 200 and $500 \mathrm{mg} / \mathrm{kg} / \mathrm{d}$ MXC accelerated the transport of embryos from the oviduct to the uterus, and in the case of $500 \mathrm{mg} / \mathrm{kg} / \mathrm{d}$, moved the embryos out of the tract altogether. ${ }^{57} \mathrm{By}$ day 3 , even $100 \mathrm{mg} / \mathrm{kg} /$ day MXC was effective in accelerating embryo transport and $200 \mathrm{mg} / \mathrm{kg} / \mathrm{d}$ MXC reduced total embryo recovery. Comparing these data with previous results where $200 \mathrm{mg} / \mathrm{kg} / \mathrm{d}$ MXC was the minimal effective dose for blocking the $\mathrm{DCR}^{56}$ and $200 \mathrm{mg} / \mathrm{kg} / \mathrm{d}$ was the lowest dose at which a significant reduction in the number of implantation sites was found,,$^{53}$ it would appear that both the acceleration of embryo transport and the inhibition of decidualization contribute in a more or less equivalent manner to the early pregnancy failure produced by MXC.

\section{Markers of MXC/Estrogen Action in the Uterus}

With the knowledge that the active metabolite of MXC, HPTE, can bind to the estrogen receptor, studies on resultant protein synthesis specific to estrogen action were performed. When immature female rats were treated with $>99 \%$ pure $\mathrm{MXC}$, a dose-dependent stimulation of the activity of uterine peroxidase was seen in the uterus. ${ }^{58}$ Concurrent treatment with actinomycin D, cycloheximide, progesterone, or tamoxifen blocked the $\mathrm{MXC}$-stimulated increase in uterine peroxidase activity, indicating a mechanism of MXC (HPTE) action that is parallel to that of estradiol. ${ }^{58}$

In a similar manner, parallels between the mechanisms of MXC at $500 \mathrm{mg} / \mathrm{kg}$ and estradiol at $10 \mu \mathrm{g} / \mathrm{rat}$ were demonstrated using the enzyme creatine kinase, a protein originally known as estrogen-induced protein or IP. Immature female rats were treated with MXC or estradiol, and IP was measured in uteri using an in vitro radiolabeling technique and the separation of labeled proteins on nondenaturing gels. Both MXC and estradiol stimulated the synthesis of IP, and concurrent treatment with actinomycin D or cycloheximide blocked the MXC-stimulated synthesis of IP. ${ }^{59}$ Immunoprecipitation of creatine kinase by a monoclonal antibody to the enzyme yielded a peak on SDS gels with a mol wt of 49,000, and SDS gels of cytosol from MXC or estradiol treated rat uteri also yielded a peak at 49,000 . Such estimates are near the established mol wt of creatine kinase of 46,000 . These data, again, demonstrate parallel mechanisms, at a biological level, between MXC (HPTE) and estradiol. ${ }^{59}$

Epidermal growth factor receptor (EGF-R) binding has been shown to be stimulated by estradiol in immature female rat uteri. ${ }^{60}$ Following the administration of either $20 \mu \mathrm{g} / \mathrm{rat}$ estradiol or $500 \mathrm{mg} / \mathrm{kg}$ MXC ( $>99 \%$ pure), the binding of ${ }^{125}$ I-labeled EGF to uterine membranes was increased ${ }^{61}$ Actinomycin D blocked the stimulation of EGF-R binding by MXC and estradiol, but cycloheximide did not. This may be due to the high doses of MXC and estradiol required to gain stimulation and the inadequacy of the near lethally toxic dose of cycloheximide $(100 \mu \mathrm{g} / \mathrm{rat})$ used to attempt blockade. Scatchard analysis revealed an increase in maximal binding $\left(\mathrm{B}_{\max }\right)$ by both MXC and estradiol and no change in the dissociation constant $\left(\mathrm{K}_{\mathrm{d}}\right)$ as a result of treatment with either chemical. ${ }^{61}$ These data also show a parallel biological mechanism between estradiol and MXC (HPTE).

\section{Teratogenic and Developmental Effects}

To evaluate the chemical's potential teratogenicity, two samples of methoxychlor were tested, technical-grade (MXT) and a formulation (MXF) containing 50\% technical methoxychlor and the rest were unknown ingredients. Treatment of rats with either sample during days 6 to 15 of gestation resulted in reduced body weight gain at doses from 50 to $400 \mathrm{mg} / \mathrm{kg} .{ }^{62}$ In addition, both types of methoxychlor were fetotoxic at 200 and $400 \mathrm{mg} / \mathrm{kg} / \mathrm{d}$. When fetuses were evaluated on gestation day 22 , both formulations were found to have produced an increase in wavy ribs at 100,200 , and $400 \mathrm{mg} / \mathrm{kg} / \mathrm{d}{ }^{62}$ These data provided the initial evidence that methoxychlor might produce developmental effects if exposure occurred during pregnancy.

Developmental landmarks were also evaluated using a different paradigm. Rats were dosed with $90 \%$ pure MXC from weaning through puberty and gestation to day 15 of lactation; doses 
ranged from 25 to $200 \mathrm{mg} / \mathrm{kg} / \mathrm{d} \mathrm{MXC}{ }^{49} \mathrm{MXC}$ was shown to accelerate the age at vaginal opening and first estrus, and vaginal smears were cornified, indicating estrogenicity of the chemical. Growth retardation was noted at 100 and $200 \mathrm{mg} / \mathrm{kg} / \mathrm{d}$ and fertility of the females was compromised. At $200 \mathrm{mg} / \mathrm{kg} / \mathrm{d}$, mated females became pseudopregnant following mating but had no implantation sites. When the offspring of the $50 \mathrm{mg} / \mathrm{kg} / \mathrm{d}$ dose group were evaluated, vaginal opening was again accelerated, estrous cyclicity was abnormal when the rats reached middle age, and fecundity was found to be reduced. ${ }^{49}$

\section{E. Effects in Males}

In the same study by Gray et al. described above, developmental effects on male rats were also observed. MXC was shown to reduce growth, seminal vesicle weight, cauda epididymal weight, caudal sperm content, and pituitary weight; puberty was also delayed. ${ }^{49}$ Pituitary levels of prolactin, thyroid-stimulating hormone, and follicle-stimulating hormone were altered and serum thyroid-stimulating hormone was reduced by $50 \%$. It should be noted that serum testosterone, $\mathrm{LH}$, and FSH were not affected, there were no effects on male pituitary size or histology, and the testes were only slightly affected with no histopathological lesions. The fertility of treated males was unaffected if bred with untreated females. ${ }^{49}$

In an early study, Tullner and Edgcomb ${ }^{63}$ examined the effect of MXC on male reproduction via pair-feeding experiments where one of each pair received 1\% MXC in the diet. Rats received MXC for 33 to $55 \mathrm{~d}$. MXC reduced body, seminal vesicle, and ventral prostate gland weights, and testicular atrophy was observed. Adrenal weights were increased and kidneys were enlarged. Histopathologic changes occurring following treatment included the finding of a lack of spermatozoa in the tubular lumina. Atypical spermatocytes were found in the seminiferous tubules, and the number of spermatocytes was reduced. Leydig cells were also decreased in number. The authors speculate that the effects of MXC on the male reproductive system may be regarded as a "consequence of the suppres- sion of production of gonadotropin by the estrogenic action of technical methoxychlor."63

In the same study by $\mathrm{Ba}^{48}$ described earlier, evaluations of the effects of MXC on the male reproductive system were also made. Technical methoxychlor was administered to adult male rats at 100 and $200 \mathrm{mg} / \mathrm{kg} / \mathrm{d}$ for $70 \mathrm{~d}$ (which encompasses the spermatogenic cycle). Results showed a degeneration of Sertoli cells and morphological abnormalities in the developmental stages of the sperm in the seminiferous tubules. Abnormalities of the ductus epididymis were also observed. Pathological alterations of the seminiferous tubules, and developing spermatozoa were also observed at the ultrastructural level. ${ }^{48}$

Goldman et al ${ }^{64}$ explored the effects of MXC on the hypothalamus and pituitary. Male rats were administered 25 or $50 \mathrm{mg} / \mathrm{kg} / \mathrm{d}$ MXC for 8 weeks beginning on day 21 of life. No changes in serumluteinizing hormone ( $\mathrm{LH})$, follicle-stimulating hormone (FSH), or prolactin or the pituitary concentrations of LH or FSH were seen. However, pituitary prolactin was elevated and when pituitary segments were perifused, the fragments released more prolactin than controls. Gonadotropin-releasing hormone $(\mathrm{GnRH})$ was elevated in the mediobasal hypothalamus at $50 \mathrm{mg} / \mathrm{kg}$. The authors suggest an interaction between the $\mathrm{GnRH}$ and prolactin levels and suggest that prolactin is important early in the adverse action of MXC on the male reproductive system.

\section{F. Effects in Mice}

Aside from the original experiments reported by Tullner, investigations of the effects of MXC on reproduction in mice have been performed only fairly recently. In 1990, Cooke and Eroschenko examined the effects of technical MXC on the development of neonatal male and female mouse reproductive tracts. ${ }^{65,66}$ The technical MXC used was shown to contain quantities of several compounds other than MXC that have estrogenic effects. Mice were treated for $10 \mathrm{~d}$, starting on day 1 of life, with $17 \beta$-estradiol or MXC at $0.05,0.1$, 0.5 , or $1.0 \mathrm{mg} / \mathrm{mouse} / \mathrm{d}$. In male mice, serum testosterone levels on day 10 were decreased; 
DNA contents of the seminal vesicles, bulbourethral glands, and ventral prostate were also reduced in both groups. ${ }^{65}$ These data indicated an inhibition of neonatal male reproductive tract development. Female mice exhibited precocious vaginal opening, complete vaginal cornification, and increased tract weight. ${ }^{66}$ In a related study, ${ }^{67}$ technical MXC was administered for $14 \mathrm{~d}$ to neonatal female mice and ultrastructural effects of the chemical were investigated in various tissues. Both 0.5 and $1.0 \mathrm{mg} / \mathrm{mouse} / \mathrm{d}$ doses of MXC increased the fluid weight of the tract and accelerated the time of vaginal opening. Ultrastructural changes in vaginal epithelium and uterine epithelium elicited by MXC differed from changes elicited by $17 \beta$-estradiol, such as uterine "pitting", uterine atypia, and distorted apical cell morphology. ${ }^{67}$

When administered to adult female mice at $1.25,2.5$, or $5 \mathrm{mg} / \mathrm{mouse}$ for 2 or 4 weeks, $50 \%$ technical-grade MXC produced persistent vaginal estrus and ovarian atrophy with atretic large follicles. ${ }^{68}$ To assess effects of the chemical on pregnancy and subsequent litters, technical MXC was administered at $2.5,5.0$, or $7.5 \mathrm{mg} / \mathrm{mouse} / \mathrm{d}$ on day 6 to 15 of pregnancy ${ }^{69}$. Female offspring were cross-fostered and sacrificed at 8 weeks of age. Dams exposed initially were rebred and the second set of litters were evaluated. The highest dose of MXC prevented the mice from carrying to term, and the length of gestation was increased by $5.0 \mathrm{mg} /$ mouse MXC. In the second set of litters, females exhibited accelerated vaginal opening; the authors suggest that this is a residual effect of MXC from the original pregnancy. ${ }^{69}$ The possibility of the passage of MXC via nursing female mice was investigated by Appel and Eroschenko. ${ }^{70}$ Technical-grade MXC was administered to lactating mouse dams for $14 \mathrm{~d}$. Suckling female pups were evaluated and alterations in their reproductive tract indicated that MXC was excreted in the milk in an active form. ${ }^{70}$

Rourke et al. ${ }^{71}$ compared the effects of technical MXC ( $1 \mathrm{mg} /$ mouse) and $17 \beta$-estradiol ( $10 \mu \mathrm{g} /$ mouse $)$ administered for $14 \mathrm{~d}$ to ovariectomized adult mice. Uterine luminal proteins were radiolabeled with ${ }^{35} S$-methionine and separated by two-dimensional gel electrophoresis. Both 17ß-estradiol and MXC altered reproductive tract weights, promoted cellular hypertrophy, and stimulated uterine develop- ment. The secretion of labeled proteins stimulated by MXC, identified after gel electrophoresis, appeared "indistinguishable" from those stimulated by $17 \beta$-estradiol. ${ }^{71}$ Further effects of $50 \%$ technical MXC on adult mice were evaluated by Swartz et al. ${ }^{72}$ in experiments where adult mice were exposed to MXC at $0.1,0.5,1.0,2.5$, or $5.0 \mathrm{mg} / \mathrm{mouse} /$ $\mathrm{d}$ for 4 weeks. Morphometric and transmission electron microscopic (TEM) studies were performed. MXC produced an increase in the height of uterine epithelial cells and increased vacuolization and swelling of mitochondria, as indicated by TEM. Effects on microvilli of the uterine epithelial cells were also observed. The authors suggest that these effects of MXC are not only estrogenic but toxic. ${ }^{72}$ It is not clear whether the toxicity is due to the estrogenic effect itself or if contaminants of the technical MXC have effects unrelated to their estrogenicity. Finally, to examine the effect of purified MXC ( $98 \%$ and base washed $98 \%$ MXC), neonatal mice received $0.05,0.5$, or $1.0 \mathrm{mg} / \mathrm{mouse} / \mathrm{d}$ for $14 \mathrm{~d}$ beginning on day 1 of life. ${ }^{73}$ Base-washed MXC had the same effect as $98 \%$ MXC and $17 \beta$ estradiol. In a manner similar to that seen in previous reports for technical MXC, 98\% pure MXC induced precocious vaginal opening, persistent vaginal estrus, increased reproductive tract weights, and epithelial hypertrophy in the vagina and uterus. ${ }^{73}$ When newborn mice received technical MXC daily for $14 \mathrm{~d}$ and were evaluated as adults, an increase in ovarian atrophy and a depletion of corpora lutea were found at 0.5 and $1.0 \mathrm{mg} \mathrm{MXC} .^{74}$ Exposure of pregnant mice to MXC during GD11GD17 led to an alteration in behavior in adult males; the rate of urine marking in male adults was increased when doses of 1,100 , or $5000 \mu \mathrm{g}$ MXC were administered to dams. ${ }^{75}$

\section{SUMMARY}

It is clear that methoxychlor is considerably less toxic than DDT, chlordecone, or other organochlorine pesticides having estrogenic activity when considered from an $\mathrm{LD}_{50}$, non- reproductive standpoint. However, reproductive toxicity is an important aspect of an evaluation of an environmental estrogen. The most sensitive of all the assays or evaluations of MXC action in rats appears to be 
vaginal opening. In the study by Gray et al., ${ }^{49}$ accelerated vaginal opening was seen in even the offspring of the groups treated with $50 \mathrm{mg} / \mathrm{kg} / \mathrm{d} \mathrm{MXC}$; $90 \%$ pure MXC was used. Also sensitive was the embryo transport rate analysis; $;{ }^{57} 100 \mathrm{mg} / \mathrm{kg} / \mathrm{d}$ accelerated embryo transport when evaluated on day 3 of pregnancy; $98 \%$ pure MXC was used. Thus, the potency of MXC in rats appears to be greatest when the purified chemical and not technical MXC is used. Experiments comparing MXC and estrone using the blockade of the decidual cell response as the endpoint suggest that MXC has $1 / 200,000$ times the activity of estradiol. ${ }^{56}$ Studies with mice used technical MXC almost exclusively. This makes comparisons with rat studies and purified MXC results difficult. However, vom Saal's study ${ }^{75}$ in which $100 \mu \mathrm{g}$ of MXC administered prenatally altered the social behavior of male offspring appears to contain the most senstitive endpoint in mice (whether technical or purified MXC was used was not reported for the latter study).

Overall, MXC can be considered a reproductive toxicant and environmental estrogen that compares with DDT in its reproductive toxicity. A metabolite of MXC binds the estrogen receptor and the chemical has effects similar to those elicited by $17 \beta$-estradiol, including the induction of specific uterine enzymes. It is estrogenic in the CNS of the adult and neonatal rat. Pregnancy is compromised by MXC administration, and deleterious effects on ovarian and uterine function are clear. Whether the dose levels sufficient to elicit reproductive effects in animals are relevant to human and environmental health is unknown at this time. The relevance to human health of the data discussed here await specific studies that address issues of exposure from experiential and epidemiological viewpoints.

\section{REFERENCES}

1. Haddad, V. and Ketchel, M. M., Termination of pregnancy and occurrence of abnormalities following estrone administration during early pregnancy, Int. $J$. Fertility, 14(1), 56, 1969.

2. Greenwald, G. S., The antifertility effects in pregnant rats of a single injection of estradiol cyclopentylpropionate, Endocrinology, 69, 1068, 1961.
3. Greenwald, G. S., Species differences in egg transport in response to exogenous estrogen, Anat. Rec., 157, 163, 1967.

4. Yochim, J. M. and DeFeo, V. J., Control of decidual growth in the rat by steroid hormones of the ovary, Endocrinology, 71, 134, 1962.

5. Yochim, J. M. and DeFeo, V. J., Hormonal control of the onset, magnitude and duration of uterine sensitivity in the rat by steroid hormones of the ovary, Endocrinology, 72, 317, 1963.

6. O'Malley, B. W. and Tsai, M-J., Molecular pathways of steroid receptor action, Biol. Reprod., 46, $163,1992$.

7. Astwood, E. B., A six-hour assay for the quantitative determination of estrogen, Endocrinology, 23, 25, 1938.

8. Cohen, S., O'Malley, B. W., and Stastny, M., Estrogen induction of ornithine decarboxylase in vivo and in vitro, Science, 170, 336, 1970.

9. Notides, A. and Gorski, J., Estrogen-induced synthesis of a specific uterine protein, Proc. Natl. Acad. Sci. U.S.A., 56, 230, 1966.

10. Reiss, N. A. and Kaye, A. M., Identification of the major component of the estrogen induced protein of rat uterus as the BB isozyme of creatine kinase, $J$. Biol. Chem., 256, 5741, 1981.

11. Lucas, F. V., Neufeld, H. A., Utterback, J. G., Martin, A. P., and Stotz, E., The effect of estrogen on the production of a peroxidase in the rat uterus, $J$. Biol. Chem., 214, 755, 1955.

12. Lyttle, C. R. and DeSombre, E. R., Uterine peroxidase as a marker for estrogen action, Proc. Natl. Acad. Sci. U.S.A., 74(8), 3162, 1977.

13. Barker, K. L. and Warren, J. C., Estrogen control of carbohydrate metabolism in the rat uterus: pathways of glucose metabolism, Endocrinology, 78, 1205, 1966.

14. Gorski, R. A., Sexual differentiation of the brain: a model for drug-induced alterations of the reproductive system, Environ. Health Persp., 70, 163, 1986.

15. McLachlan, J. A., Newbold, R. R., Shah, H. C., Hogan, M. D., and Dixon, R. L., Reduced fertility in female mice exposed transplacentally to diethylstilbestrol (DES), Fertil. Steril., 38(3), 364, 1982.

16. Newbold, R. R. and McLachlan, J. A., Diethylstilbestrol-associated defects in murine genital tract development, in Estrogens in the Environment II: Influences on Development, McLachlan, J. A., Ed. Elsevier North-Holland, New York, 1985, 288.

17. Burlington, H. and Lindeman, V. F., Effect of DDT on testes and secondary sex characteristics of white leghorn cockerels, Proc. Soc. Exp. Biol. Med., 74, 48, 1950.

18. Fisher, A. L., Keasling, H. H., and Scheuler, F. W., Estrogenic action of some DDT analogues, Proc. Soc. Exp. Biol. Med., 81, 439, 1952.

19. Bitman, J., Cecil, H. C., Harris, S. J., and Fries, G. F., Estrogenic activity of $o, p^{\prime}$-DDT in the mammalian uterus and avian opiduct, Science, 162, 371, 1968. 
20. Gellert, R. J., Heinrichs, W. L., and Swerdloff, R. S., DDT homologues: estrogen-like effects on the vagina, uterus and pituitary of the rat, Endocrinology, 91, 1095,1972

21. Guzelian, P. S., Comparative toxicology of chlordecone (Kepone) in humans and experimental animals, Ann. Rev. Pharmacol. Toxicol., 22, 89, 1982.

22. Gellert, R. J., Kepone, Mirex, dieldrin, and aldrin: estrogenic activity and the induction of persistent vaginal estrus and anovulation in rats following neonatal treatment, Environ. Res., 16, 131, 1978.

23. Gellert, R. J., Uterotrophic activity of polychlorinated biphenyls (PCB) and induction of precocious reproductive aging in neonatally treated female rats, Environ. Res., 16, 123, 1978.

24. Bitman, J. and Cecil, H. C., Estrogenic activity of DDT analogues and polychlorinated biphenyls, J. Agric. Food Chem., 18(6), 1108, 1970.

25. White, R., Jobling, S., Hoare, S. A., Sumpter, J. P., and Parker, M. G., Environmentally persistent alkylphenolic compounds are estrogenic, Endocrinology, 135, 175, 1994.

26. Anonymous, IARC Monographs on the Evaluation of the Carcinogenic Risk of Chemicals to Humans, 259, 1979.

27. Duggan, R. E., Corneliussen, P. E., Duggan, M. G., McMahon, B. M., and Martin, R. J., Pesticide residue levels in foods in the United States from July 1, 1969 to June 10, 1976, Food and Drug Admin. and Assoc. of Official Anal. Chem., Washington D.C., 1983.

28. Kapoor, I. P., Metcalf, R. L., Nystrom, R. F., and Sangha, G. K., Comparative metabolism of methoxychlor, methiochlor, and DTT in mouse, insects, and in a model ecosystem, J. Agric. Food Chem., 18(6), 1145, 1970

29. U.S.E.P.A. Office of Drinking Water, Methoxychlor, Rev. Environ. Contam. Toxicol. 104, 161, 1988.

30. Hodge, H. C., Maynard, E. A., and Blanchet, H. J., Jr., Chronic oral toxicity tests of methoxychlor $(2,2-$ di( $p$-methoxyphenyl)-1,1,1-trichloroethane) in rats and dogs, J. Pharmacol. Exp. Therapeut., 104, 60, 1952.

31. Hodge, H. C., Maynard, E. A., Thomas, J. F., Blanchet, H. J., Jr., Wilt, W. G., Jr., and Mason, K. E., Shortterm oral toxicity tests of methoxychlor $(2,2 \mathrm{di}-(p$ methoxyphenyl)-1,1,1-trichlorethane) in rats and dogs, J. Pharmacol. Exp. Therap., 99. 140, 1950.

32. Kumar, S. and Pant, S. C., Comparative sublethal ovarian pathology of some pesticides in the teleost Puntius conchonius Hamilton, Bull. Environ. Contam. Toxicol., 41, 227, 1988.

33. Radomski, J. L, Deichmann, W. B., MacDonald, W. E., and Glass, E. M., Synergism among oral carcinogens. I. Results of the simultaneous feeding of four tumorigens to rats, Toxocol. Appl. Pharmacol., $7(5), 652,1965$

34. Deichmann, W. B., Keplinger, M., Sala, F., and Glass, E., Synergism among oral carcinogens. IV. The simultaneous feeding of four tumorigens to rats, Toxicol. Appl. Pharmacol., 11, 88, 1967.
35. Reuber, M. D., Carcinogenicity and toxicity of methoxychlor, Environ. Health Perspect., 36, 205, 1980.

36. Oberly, T. J., Michaelis, K. C., Rexroat, M. A. Bewsey, B. J., and Garriot, M. L., A comparison of the $\mathrm{CHO} / \mathrm{HGPRT}+$ and the $\mathrm{L} 5178 \mathrm{Y} / \mathrm{TK}+/$ - mutation assays using suspension treatment and soft agar cloning: results for 10 chemicals, Cell Biol. Toxicol., 9, 243, 1993.

37. National Cancer Institute, Bioassay of methoxychlor for possible carcinogenicity, NCl-CG-TR-35 Carcinogenesis Program, 91, 1978.

38. Welch, R. M., Levin, W., and Conney, A. H., Estrogenic action of DDT and its analogs, Toxicol. Appl. Pharmacol., 14, 358, 1969.

39. Nelson, A., Effects of dichlorophenyltrichloroethane (DDT) analogs and polychlorinated biphenyl (PCB) mixtures on $17 \beta-\left[{ }^{3} \mathrm{H}\right]$-estradiol binding to rat uterine estrogen receptor, Biochem. Pharmacol., 23, 447, 1974.

40. Kupfer, D., Effects of pesticides and related compounds on steroid metabolism and function, Crit. Rev. Toxicol., 4, 83, 1975.

41. Nelson, J. A., Struck, R. F., and James, R., Estrogenic activities of chlorinated hydrocarbons, J. Toxicol. Environ. Health, 4, 325, 1978.

42. Bulger, W. H., Muccitelli, R. M., and Kupfer, D., Interactions of methoxychlor, methoxychlor base soluble contaminant, and 2,2-bis( $p$-hydroxyphenyl)-1,1,1trichloroethane with rat uterine estrogen receptor, $J$. Toxicol. Environ. Health, 4, 881, 1978.

43. Bulger, W. H., Muccitelli, R. M., and Kupfer, D., Studies on the in vivo and in vitro estrogenic activities of methoxychlor and its metabolites. Role of hepatic mono-oxygenase in methoxychlor activation, Biochem. Pharmacol., 27, 2417, 1978.

44. Kupfer, D. and Bulger, W. H., A novel in vitro method for demonstrating proestrogens. Metabolism of methoxychlor and $o, p^{\prime}$ DDT by liver microsomes in the presence of uteri and effects on intracellular distribution of estrogen receptors, Life Sci., 25, 975, 1979.

45. Ousterhout, J. M., Struck, R. F., and Nelson, J. A., Estrogenic properties of methoxychlor metabolites, Fed. Proc. Fed. Am. Soc. Exp. Biol., 38 (3 [Pt.1]), 537, 1979.

46. Bulger, W. H., Feil, V. J., and Kupfer, D., Role of hepatic monooxygenases in generating estrogenic metabolites from methoxychlor and from its identified contaminants, Mol. Pharmacol., 27, 115, 1985.

47. Harris, S. J., Cecil, H. C., and Bitman, J., Effect of several dietary levels of technical methoxychlor on reproduction in rats, J. Agric. Food Chem., 22(6), 969, 1974.

48. Bal, H. S., Effect of methoxychlor on reproductive systems of the rat, Proc. Soc. Exp. Biol. Med., 176, 187, 1984.

49. Gray, L. E., Jr., Ostby, J., Ferrell, J., Rehnberg, G., Linder, R., Cooper, R., Goldman, J., Slott, V., and Laskey, J., A dose-response analysis of methoxychlor-induced alterations of reproductive development and function in the rat, Fund. Appl. Toxicol., 12, 92, 1989 
50. Tullner, W. W., Uterotropic action of the insecticide methoxychlor, Science, 133, 647, 1961.

51. Johnson, D. C., Sen, M., and Dey, S. K., Differential effects of dichlorodiphenyltrichloroethane analogs, chlordecone, and 2,3,7,8-tetrachlorodibenzp- $p$-dioxin on establishment of pregnancy in the hypophysectomized rat, Proc. Soc. Exp. Biol. Med., 199, 42, 1992.

52. Gray, L. E., Jr., Ostby, J. S., Ferrell, J. M., Sigmon, E. R., and Goldman, J. M., Methoxychlor induces estrogen-like alterations of behavior and the reproductive tract in the female rat and hamster: effects on sex behavior, running wheel activity, and uterine morphology, Toxicol. Appl. Pharmacol., 96, 525, 1988.

53. Cummings, A. M. and Gray, L. E., Jr., Antifertility effect of methoxychlor in female rats: dose- and timedependent blockade of pregnancy, Toxicol. Appl. Pharmacol., 97, 454, 1989.

54. DeFeo, V. J., Temporal aspect of uterine sensitivity in the pseudopregnant rat, Endocrinology, 72, 305, 1963.

55. DeFeo, V. J., Decidualization, in: Wynn, R. M., Ed., Cellular Biology of the Uterus, Appleton-CenturyCrofts/Meredith, New York, 1967, 191.

56. Cummings, A. M. and Gray L. E., Jr., Methoxychlor affects the decidual cell response of the uterus but not other progestational parameters in female rats, Toxicol. Appl. Pharmacol., 90, 330, 1987.

57. Cummings, A. M. and Perreault, S. D., Methoxychlor accelerates embryo transport through the rat reproductive tract, Toxicol. Appl. Pharmacol., 102, 110, 1990.

58. Cummings, A. M. and Metcalf, J. M., Mechanisms of the stimulation of rat uterine peroxidase activity by methoxychlor, Reprod. Toxicol., 8(6), 477, 1994.

59. Cummings, A. M. and Metcalf, J. M., Methoxychlor regulates rat uterine estrogen-induced protein, Toxicol. Appl. Pharmacol., 130, 154, 1995.

60. Mukku, V. R. and Stancel, G. M., Regulation of epidermal growth factor receptor by estrogen, J. Biol. Chem., 260, 9820, 1985.

61. Metcalf, J. L, Laws, S. C., and Cummings, A. M., Methoxychlor mimics the action of $17 \beta$ estradiol on induction of uterine epidermal growth factor receptors in immature female rats, Biol. Reprod., 52(Suppl. 1), 97, 1995.

62. Khera, K. S., Whalen, C., and Trivett, G., Teratogenicity studies on Linuron, Malathion, and Methoxychlor in rats, Toxicol. Appl. Pharmacol., 45, 435, 1978.

63. Tullner, W. W. and Edgcomb, J. H., Cystic tubular nephropathy and decrease in testicular weight in rats following oral methoxychlor treatment, J. Pharmacol. Exp. Ther., 138, 126, 1962.

64. Goldman, J. M., Cooper, R. L., Rehnberg, G. L., Hein, J. F., McElroy, W. K. and Gray, L. E., Jr., Effects of low subchronic doses of methoxychlor on the rat hypothalamic-pituitary reproductive axis, Toxicol. Appl. Pharmacol., 86, 474, 1986.

65. Cooke, P. S. and Eroschenko, V. P., Inhibitory effects of technical-grade methoxychlor on development of neonatal mouse reproductive organs, Biol. Reprod., 42, 585, 1990.

66. Eroschenko, V. P. and Cooke, P. S., Morphological and biochemical alterations in reproductive tracts of neonatal female mice treated with the pesticide methoxychlor, Biol. Reprod., 42, 573, 1990.

67. Eroschenko, V.P., Ultrastructure of vagina and uterus in young mice after methoxychlor exposure, Reprod. Toxicol., 5, 427, 1991.

68. Martinez, E. M. and Swartz, W. J., Effects of methoxychlor on the reproductive system of the adult female mouse. I. Gross and histological observations, Reprod. Toxicol., 5, 139, 1991.

69. Swartz, W. J. and Corkern, M., Effects of methoxychlor treatment of pregnant mice on female offspring of the treated and subsequent pregnancies, Reprod. Toxicol., 6, 431, 1992.

70. Appel, R. J. and Eroschenko, V. P., Passage of methoxychlor in milk and reproductive organs of nursing female mice. I. Light and scanning electron microscopic observations, Reprod. Toxicol., 6, 223, 1992.

71. Rourke, A. W., Eroschenko, V. P., and Washburn, L. J., Protein secretions in mouse uterus after methoxychlor or estradiol exposure, Reprod. Toxicol., 5, 437, 1991.

72. Swartz, W. J., Wink, C., and Johnson, W. D., Response of adult murine uterine epithelium to $50 \%$ methoxychlor, Reprod. Toxicol., 8, 81, 1994.

73. Walters, L. M., Rourke, A. W., and Eroschenko, V.P., Purified methoxychlor stimulates the reproductive tract in immature female mice, Reprod. Toxicol., 7, 599, 1993.

74. Eroschenko, V. P., Abuel-Atta, A. A., and Grober, M.S., Neonatal exposures to technical methoxychlor alters ovaries in adult mice, Reprod. Toxicol., 9(4), 379, 1995.

75. vom Saal, F. S., Nagel, S. C., Palanza, P., Boechler, M., Parmigiani, S., and Welshons, W. V., Estrogenic pesticides: binding relative to estradiol in MCF-7 cells and effects of exposure during fetal life on subsequent territorial behavior in male mice, Toxicol. Lett., 77, 343, 1995. 